\title{
Technological developments as an answer to bridge management challenges
}

\begin{tabular}{|c|c|}
\hline Journal: & IABSE Guimaraes 2019 \\
\hline Manuscript ID & GUI-0334-2019.R1 \\
\hline Theme: & Lifecycle Quality Control of New and Existing Infrastructures \\
\hline $\begin{array}{r}\text { Date Submitted by the } \\
\text { Author: }\end{array}$ & $\mathrm{n} / \mathrm{a}$ \\
\hline Complete List of Authors: & $\begin{array}{l}\text { Orcesi, Andre; IFSTTAR, MAST } \\
\text { GODART, Bruno; IFSTTAR, MAST } \\
\text { Gaillet, Laurent; Schmidt, Franziska; IFSTTAR, MAST } \\
\text { Bardou, Nicolas; Cofiroute } \\
\text { Limongelli, Maria Pina; Politrcnico di Milano, Architecture, Built } \\
\text { Environment, Construction Engineering } \\
\text { Carreaud, Pierre; SITES Rhône-Alpes } \\
\text { Lenoir, François; ADISS } \\
\text { Baron, Gérard; OSMOS }\end{array}$ \\
\hline Keywords: & $\begin{array}{l}\text { Bridges < Type of Structure, Inspection and Maintenance }<\text { Other } \\
\text { Aspects, Testing < Other Aspects }\end{array}$ \\
\hline
\end{tabular}

\section{SCHOLARONE \\ Manuscripts}




\title{
Technological developments as an answer to bridge management challenges
}

\author{
André Orcesi, Bruno Godart, Laurent Gaillet, Franziska Schmidt \\ Université Paris-Est, MAST, IFSTTAR, France
}

Nicolas Bardou

Vinci autoroutes, Rueil-Malmaison, France

Maria Pina Limongelli

Politecnico di Milano, Milano, Italy

Pierre Carreaud

SITES Rhône-Alpes, Ecully, France

François Lenoir

ADISS, Lille, France

François Gérard BARON

OSMOS GROUP, France

Contacting author: andre.orcesi@ifsttar.fr

\begin{abstract}
Bridge management is a challenge as owners have to deal with limited financial resources to maintain the functionalities and safety of ageing structures. Demands on transportation networks change, due to regulatory developments, society's evolution and shifts with high expectations on the operational performance of roadway bridges with reduced congestion, delay, and accidents. To minimize intrusion in the transport flow, inspection and monitoring methods should be non-destructive, minimally invasive. They should be capable of yielding rapid and accurate inspection results allowing an adequate response from the asset manager. Research aims at including autonomously operating equipment (e.g. robotics), non-intrusive (remote or proximity) observation techniques, or other methods that ensure quality and performance control of the roadway bridges in time, more safely, more quickly and/or to a higher degree of accuracy and precision. The innovation subgroup in COST action TU1406 investigates novel condition monitoring and sensing technologies for the assessment of structural serviceability and safety. Advanced, integrated, cost-effective and reliable instrumentation solutions, techniques and concepts are looked at with the aim to provide data, that will be used to compute innovative performance indicators. In this context, this paper briefly reminds some significant challenges associated with bridge management and presents three examples of innovation in bridge monitoring and NDT investigation techniques.
\end{abstract}

Keywords: innovation, bridge, SHM, inspection, high resolution photography, NDT, cables, WIM. 


\title{
Technological developments as an answer to bridge management challenges
}

\author{
André Orcesi, Bruno Godart, Laurent Gaillet, Franziska Schmidt \\ Université Paris-Est, MAST, IFSTTAR, France
}

Nicolas Bardou

Vinci autoroutes, Rueil-Malmaison, France

Maria Pina Limongelli

Politecnico di Milano, Milano, Italy

Pierre Carreaud

SITES Rhône-Alpes, Ecully, France

François Lenoir

ADISS, Lille, France

François Gérard BARON

OSMOS GROUP, France

Contacting author: andre.orcesi@ifsttar.fr

\begin{abstract}
Bridge management is a challenge as owners have to deal with limited financial resources to maintain the functionalities and safety of ageing structures. Demands on transportation networks change, due to regulatory developments, society's evolution and shifts with high expectations on the operational performance of roadway bridges with reduced congestion, delay, and accidents. To minimize intrusion in the transport flow, inspection and monitoring methods should be non-destructive, minimally invasive. They should be capable of yielding rapid and accurate inspection results allowing an adequate response from the asset manager. Research aims at including autonomously operating equipment (e.g. robotics), non-intrusive (remote or proximity) observation techniques, or other methods that ensure quality and performance control of the roadway bridges in time, more safely, more quickly and/or to a higher degree of accuracy and precision. The innovation subgroup in COST action TU1406 investigates novel condition monitoring and sensing technologies for the assessment of structural serviceability and safety. Advanced, integrated, cost-effective and reliable instrumentation solutions, techniques and concepts are looked at with the aim to provide data, that will be used to compute innovative performance indicators. In this context, this paper briefly reminds some significant challenges associated with bridge management and presents three examples of innovation in bridge monitoring and NDT investigation techniques.
\end{abstract}

Keywords: innovation, bridge, SHM, inspection, high resolution photography, NDT, cables, WIM.

\section{Introduction}

Many bridge managers across Western countries are experiencing similar issues when dealing with preservation of transportation infrastructure networks: (i) they have to manage ageing bridges generally exposed to operating conditions that are significantly different from those at the design 
IABSE Symposium 2019 Guimarães: Towards a Resilient Built Environment - Risk and Asset Management March 27-29, 2019, Guimarães, Portugal

stage. More specifically, such changes are due to traffic growth (in both intensity and frequency); (ii) the majority of these bridge managers also face significant budgetary cuts. As a result, results are not anymore adequate - nor in terms of technical staff and in economic terms - for managing and maintaining bridges in an efficient way. In some countries, state decentralization processes have sometimes transferred infrastructure management to non-technical authorities unable of addressing such technical responsibilities; (iii) besides, expectations of citizens and decision makers are continuously rising. They are requesting more transparency and more safety, less socio-economic impact and more consideration of environmental issues; (iv) operating and management responsibilities are becoming increasingly complex. Bridge managers, who essentially have technical backgrounds, have now to learn how to integrate more broadly all the expectations and issues of their surrounding environments, yet most of which do not originally fall under civil engineering area of expertise; (v) the profession is evolving and available tools for bridge management are no longer sufficient but, at the same time, many recent events across Europe demonstrate how important and significant the role of bridge managers can be.

The work of COST action TU1406 partly addresses this problematic [1] with an approach based on the sharing of experiences at an international level in order to foster synergies to meet up these new challenges. This is one of the reasons why the COST ACTION TU1406 management board invited a dedicated committee of advisers with bridge management expertise. This team consists of public and private bridges managers, consultants, experts from research institutes and engineering offices. Its role is to ensure the practical and operational dimension of COST TU1406 work. One effective answers to both managers' and citizens' expectations, who aspire to more reliable and safe infrastructure networks, dwells in Innovation that, in COST Action TU1406 is tackled by the Innovation Subgroup. The work in the innovation subgroup focuses on innovative indicators for quality checks of bridges [2] and on technological innovations that can improve accuracy and precision of quality controls of roadway bridges thus achieving higher performances in terms of safety and availability.

The three examples introduced in this paper are examples of innovative technologies for condition assessment. The first one explores the vast potential and advantages of contact-free innovative monitoring techniques based on very high-resolution camera acquisitions. The second one presents a number of non-destructive testing for critical bridge elements like cables, ropes and pre-stressed components. The third one relates to bridge weigh in motion (WIM) tools to assess the traffic level and the associated increase in structural performance demands.

\section{High resolution photography}

This section presents the context that called for new inspection techniques, the development of high efficiency tools by SITES, and some applications based on these innovative tools.

\subsection{Constraints and motivations}

Large civil engineering structures, especially those dedicated to transportation and networks such roadway or railway bridges and tunnels, require constant monitoring to ensure their safety and serviceability. The scale of these elongated structures, coupled with often complex and/or dangerous access to elements to inspect, tends to limit the frequency of on-site interventions. Moreover, most of these structures have a significant contribution to local or regional economic development, therefore minimum service interruption and disturbance to users are required. In this context, efficiency of inspection and processing should be optimized while guaranteeing both accuracy and repeatability. Solutions based on high resolution camera acquisition [3] may help meet these objectives.

\subsection{Very High Resolution Photographic Inspection (VHRPI)}

Very high resolution digital cameras, with specific lens and calibration (according to the light conditions and distance) are used to generate semi-automatically panoramic views of the structure that are used for an off-site inspection. Report of observed features and anomalies are 
performed manually afterwards. The use of high definition hardware allows high accuracy in the inspection and detection of defects. This allows the user to monitor the appearance and the opening of cracks over time, and to map them with accuracy (Figure 1). These data about crack density and severity allow to describe the health state of the structure.
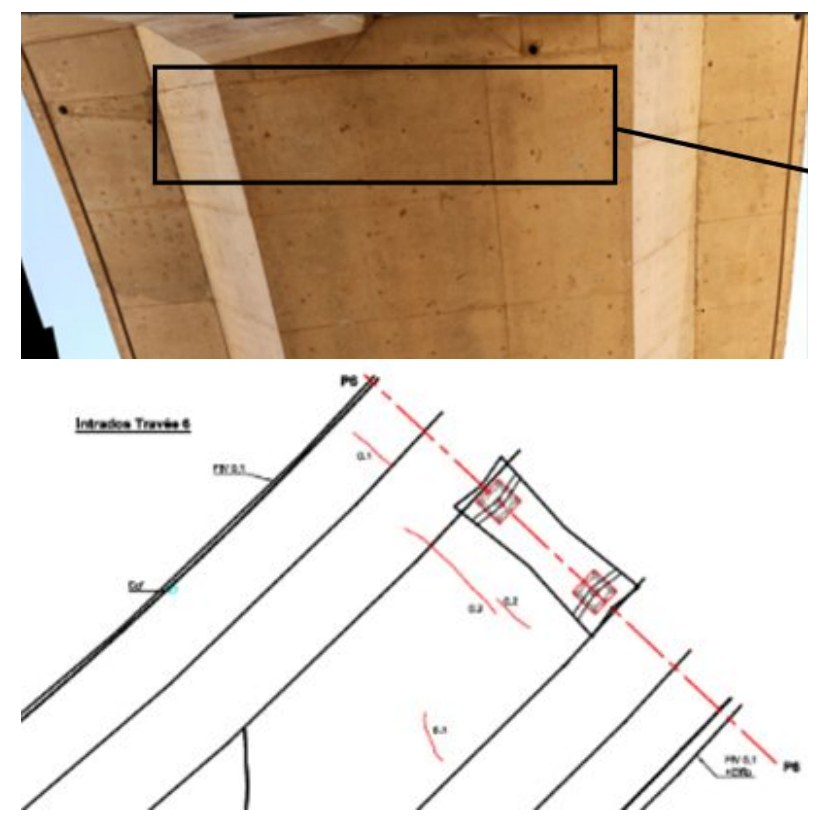

Figure 1. VHRPI application on a viaduct in Oran (Up: HR picture, Down: cracks mapping)

To increase efficiency of interventions, solutions to automate data acquisition and mapping of anomalies have been developed. One developed tool is the ScanSites solution. It consists of a combination of Very High Resolution camera mounted on robotized head, with GIS (Geographic Information System) software. This solution permits real-time observation, detection and localization of defects. With progressive upgrades, the system now has the ability to detect cracks down to $0.1 \mathrm{~mm}$ at $200 \mathrm{~m}$ distance, and to estimate their position with centimetric accuracy, this tool is very efficient for large structures like roadbridges. These automated acquisition tools can be combined with Lidar and/or photogrammetric processing in order to produce referenced multilayer numerical models with both cracks and deformation information [4].

The inspection of inner areas, such as tunnels or the interior of bridges, can be tackled with $360^{\circ}$ panoramic tools ScanTubes, which is equipped with a number of calibrated high definition cameras that allow to maximise the inspection speed of tunnels. The system allows for high precision visual inspection, but also relies on photogrammetric processing in order to produce a high definition 3D model of the structure (Figure 2). In railway tunnel applications, it allows defects detection down to $0.05 \mathrm{~mm}$, and was proven able to scan up to $6 \mathrm{~km}$ of tunnels in less than $4 \mathrm{~h}$. An original application of the $360^{\circ}$ panoramic tool that overcomes limitations related to human inspections, consists in using it to inspect vertical structural components [5]. This enables for example both 3D modelling and defect inspection of hollow viaduct piers.
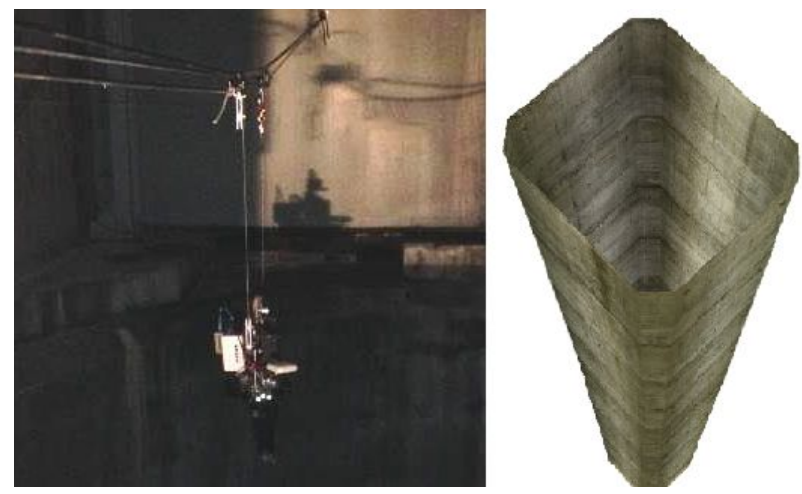

Figure 2. Left: suspended ScanTube system, Right: 3D model of an hollow pier

Further developments of this technology focus on the increase of acquisition speed, the reduction of noise, and the application of big data processing software. Moreover while cracks mapping gives an insight about the structural health, a clear definition of a "crack index" transferable from one structure to another is not yet available. The achievement of a precise operational definition will require further research efforts.

\section{NDT for bridge cables, ropes and prestressed concrete elements}

\subsection{Gamma- or X-ray radiography for detection of voids in tendon ducts}

The detection of voids in grouted tendon ducts in concrete structures is crucial. Commonly used for decades, the gamma- or X-ray radiography technique provides a reliable diagnosis of the quality of the grouting [6]. In some cases, one can 
detect anomalies like abnormal deformations, wire or strands failures, as well as distensions of wires [7]. This powerful technique unfortunately has the disadvantage of requiring a large security zone for radiation protection of the operator as well as the people in the vicinity [6]. Besides, it is an expensive technique for a relatively limited length of tested tendon. The examinations are local $(30 \mathrm{~cm} \times 40 \mathrm{~cm}$ picture) and need an important gamma-ray exposure duration which is a function of the thickness of the investigated structure. The numerical radiography is developing.

\subsection{Impact echo technique as an alternative to Gamma- or X-ray radiography?}

Since the end of the 1980s, the impact-echo method has also been proposed [6-8]. It is based on a frequential analysis of the time response of a structure excited by a shock. Shifts in the frequencies due to changes of the duct depth and of the slab thickness have been used as indicators of voids in ducts [8]. The advantages of impact echo lie in the simplicity of experimental set-up that requires access to only one side [7]. Two major phenomena are indicative of the presence of a void in the impact echo method: a decrease of the thickness resonance frequency $f_{e}$ and the apparition of a higher frequency, named $f_{\text {void }}$ in the literature . The first observable alone might be in a number of case misleading since a frequency shift has been sometime observed in tendon that are diagnosed as fully grouted by gammagraphy. The addition of the second observable $\left(f_{\text {void }}\right)$ that confirms the existence of a void can ascertain the diagnosis [9].

Some device is commercialized for void detection in prestress ducts but still requires some research developments [7]. In particular, the high frequency content of the impact echo signal is difficult to record, first because sending energy in this frequency range is difficult, second due to the existence of scattering and damping, and third because traditional contact transducer are not optimal in this frequency range [9]. Abraham et al. [9] recently considered the use of a laser interferometer which has a large bandwidth and which offers the possibility to record simultaneously both observables.

\subsection{The capacity probe for detecting voids and white paste in external HDPE ducts}

This technique was developed to detect voids or the presence of white paste in an external tendon in a HDPE duct filled by a cement grout [10]. The device consists of two electrodes constituting a capacitor whose capacity depends on the dielectric characteristics of the materials existing inside the HDPE duct. It allows to detect grouting defects. Its depth of investigation is between 1 and $3 \mathrm{~cm}$. The device is light to handle along the duct, but the technique cannot detect the corrosion of strands or the presence of liquid inside the duct.

\subsection{The US tomography for detecting voids in prestressing tendons}

This technology [11] consists of simultaneously sending and receiving ultrasonic waves through a material, using several transmitters/transducers at frequencies ranging from 25 to $75 \mathrm{kHz}$.

A software integrated in the device analyses the travel times of these waves making possible the detection of heterogeneities in the tested material (Figure 3). The restitution is a coloured cartography visualizing the different zones. This method is effective for the detection of voids in prestressing cables and as such can be an alternative to the use of radiography when it is too restrictive.

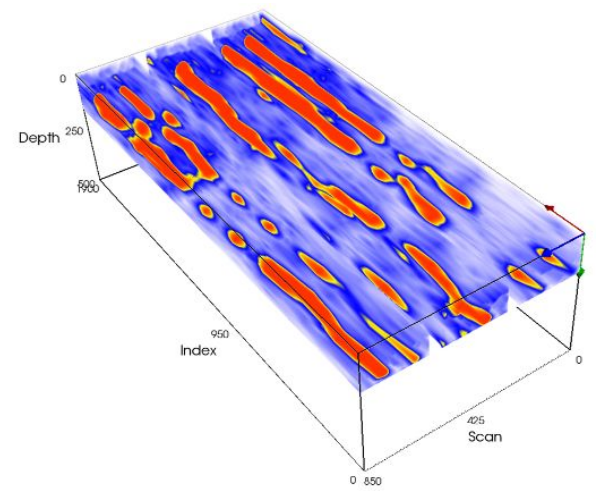

Figure 3. Example of images obtained using Ultrasonic Tomography. 


\subsection{Electromagnetic techniques to detect corrosion of cables}

Electromagnetic method uses magnetic inductance scanning. Cable elements, being metallic, are highly susceptible to electromagnetic fields. In this method, a strong magnetic field is generated around the steel cable with the help of an electromagnetic coil. Corrosion defects are changing the boundary conditions of the field and therefore causing a field disturbance that can be detected by the device [12].

\subsection{Magnetic flux leakage (MFL) for broken wires detection}

Magnetic flux leakage is a NDT method used to detect defects and corrosion in steel structures, especially for stay cables with large diameters. The basic principle is that a powerful magnet is used to magnetize the steel [13]. At areas where there is corrosion or missing metal, the magnetic field "leaks" from the steel. By placing a magnetic detector between the poles of the magnet, one can then detect the leakage field and, indirectly, the flaws of the cables. However, MFL method can only detect the local fault near the surface: hidden damage at the inside of large cable will not be detected [14].

\subsection{Ultrasonic and acoustic techniques for inaccessible areas}

Among the major suspension bridge components, cables and anchorage zones are critical locations. Indeed, cables are primarily undergoing environmental aggressions and the anchorage zone, often an inaccessible part of the bridge located at the bottom of the retaining cables, provides an ideal location for water accumulation that promotes the development of corrosion [15].

The acoustic emission ( $\mathrm{AE}$ ) technique is based on the release of stored elastic energy as elastic waves due to sudden micro-fracturing in a rigid body. In the last decades several developments focused on the detection of wire rupture of suspension and stay cables and prestressing tendons [16-18].

The ultrasonic guided waves method is another technique, particularly suitable for anchorage zones. It is used to inspect each individual wire of strands and allows detecting net breaks of wires close to the anchorage area, along the guiding direction. It is potentially attractive for the inspection of anchorages embedded in massive concrete blocks. This technique is already used in industrial applications and is continuously improved by an active community in the world [17, 19-21].

The Acousto-Ultrasonic technique is relatively new in civil engineering for defect detection. This technique combines aspects of acoustic emission signal analysis with ultrasonics assessment methods. The transmitter transducer generates a specific ultrasonic waveform that propagates through the specimen before being collected by a receiver transducer. Signals resulting from multiple reflections and interactions with the microstructure of the material are treated in the same way as acoustic emission signals. Kharrat \& Gaillet [15] compared the Acousto-Ultrasonic technique with classical ultrasonics testing method for damage detection in anchorage zones. The former is useful for evaluating the global structural health of the anchorage zones, whereas the latter would be rather suitable for detecting local and crack-like defects.

\section{Weigh in motion systems (WIM)}

\subsection{Updating remaining fatigue service life with WIM information}

Using recorded traffic data makes it possible to infer the consequences of traffic regulation changes for example on pavement (changes in the fatigue and rutting), on geometrical constraints (geometry of the road and ability to drive on the existing infrastructure) and on bridge loading. In a recent study [22], the impact on the bridge lifetimes of the increase of the limit of $40 \mathrm{t}$ to $44 \mathrm{t}$ for GVW of 5 axle-trucks has been investigated. Weigh-in-motion data have been used in order to obtain an accurate description of the actual traffic volumes and loads (Figure 4). Such traffic information has then been modified in order to account for the regulations changes. The very simple and crude assumptions done were that (i) the gross weight of every heavy vehicle in the 
range between 36 and 44 tons was increased by $10 \%$, the additional weight being uniformly distributed on all axes; (ii) all the other vehicles were assigned the same load as before (volume limitation or not enough freight to carry).The effects on bridges were calculated by applying these traffic loads, either directly as measured by WIM systems or simulated, on influence lines or surfaces. The increase of the extreme stresses was limited to 6.5 or $8.5 \%$, on a $40 \mathrm{~m}$ simple supported span (bending moment at mid span effect), carrying three traffic lanes. The reduction of the lifetime, whatever the fatigue resistance (S-N class) and the bridge, remained below $20 \%$.

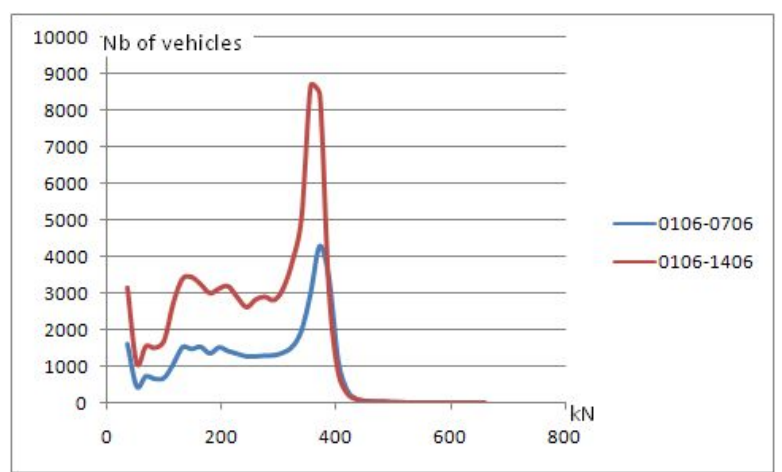

Figure 4. Gross weight distributions on the slow lane of the A9 motorway, 1 \& 2 weeks in June 2009.

\subsection{The use of fibre optical strands for WIM applications}

This section describes a methodology gathering data concerning the measurement of live loads as well as the monitoring of the relevant effects on the structure itself. Within the context of a dramatic increase of the trucks cross border traffic and the number of overloaded convoys, bridge asset managers are more and more facing the need of accurate tools to measure the transiting loads on their networks.

Existing WIM (weigh in motion) systems are most of the time intrusive to road coating, costly and they must be removed during the pavement maintenance. The hereinafter technology, so called WIM+D, uses the bridge deck as a weighing platform [23]. Not intrusive to the pavement, it offers the possibility to be coupled with a SHM system, using the same sensors and a unique data acquisition unit. The OSMOS WIM+D application provides both weigh in motion measurements and strain monitoring with a single set of sensors and data acquisition unit. The SHM system measures strains on the bridge deck using long fibre optical strands (Figure 5). The sensors relies on micro wave technology based on light's continuous intensity modulation. The light attenuations are directly correlated to the deformation of the optical strand.

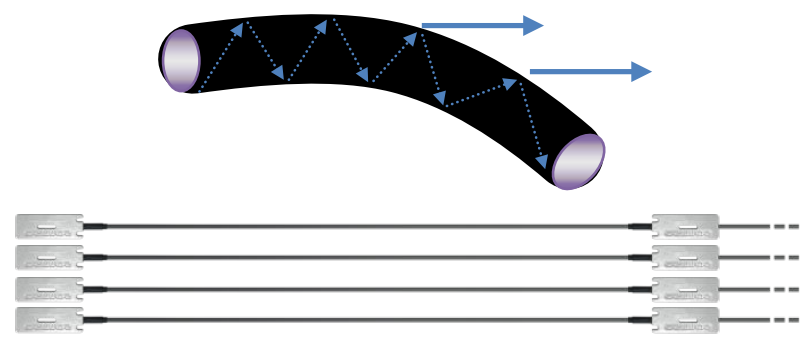

Figure 5. Optical strands

\subsection{The WIM+D framework}

The system OSMOS WIM+D consists in installing optical strands under two consecutive spans to record the most significant strain variations due to the bending under the effect of the live loads. The data are processed with proprietary algorithms and the information given are (Figure 6): gross weight, speed, direction, maximal strain in the main elements, length of the truck, number of axles, axles distance, axle load for each axle. As mentioned, in addition to the weighing system the OSMOS WIM+D provides, with the same Optical strands technology, an efficient structural monitoring (Figure 7).

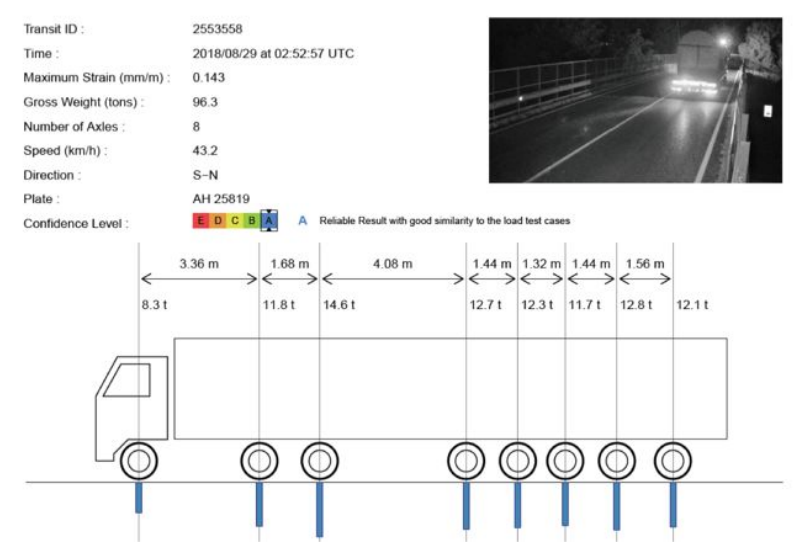

Figure 6. Passage data sheet

The performance of the technology varies according to the type of bridge, the speed and the load. In any case, an indicator of the confidence 
level of the measured strains is given. The structural health monitoring is performed with a limited number of sensors (OS) implemented on the same spans. These additional measurements enable the detection of abnormalities of structure, the ageing trends, and eventually, through forecast models, the residual service life.

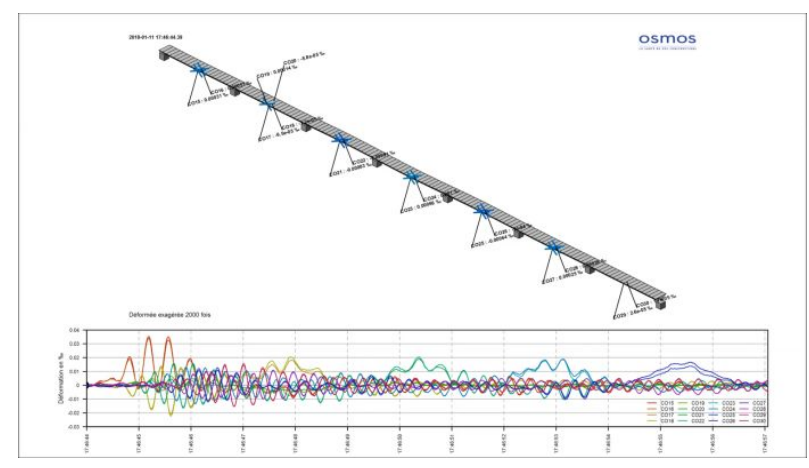

Figure 7. Strain monitoring on a prestressed bridge.

\section{Conclusions}

The examples presented in this paper show some innovative inspection, monitoring and investigation technologies where the aim is to easily translate raw data into actionable data to implement into asset management. Technological developments should provide owners with tools predicting in a quantitative way the future degradation of elements as well as the associated uncertainties as well as changes in traffic loading. Main objective is the minimization of consequences, should they be societal, environmental or economic, caused by inadequate functioning or by unexpected structural failure, of a component, a system or an equipment. Issues are numerous and their difficulty is not least. Nevertheless, many opportunities should help to meet up these challenges. Digitalisation, which evolution is progressing rapidly, already presents promising research leads. The Internet of Things, mobility "as a service", artificial intelligence and autonomous vehicles are already present on infrastructures. These technologies will help develop both innovative and new solutions for bridges managers. We have never had so much data available. The means to acquire these data should, whether using automatic or semiautomatic tools, makes it possible to improve its reliability and to diversify the type of data collected (thanks to new sensors). Big data and machine learning tools will also enable improving the use of data, in particular to establish behavioural models of bridges.

\section{References}

[1] Matos, J. C., Casas, J. R. and Fernandes, S. COST Action TU 1406 Quality Specifications for Roadway Bridges (BridgeSpec). in Proceedings of 8th international conference on Bridge Maintenance, Safety and Management, Foz do Iguacu, Brazil, 2016.

[2] Limongelli, M.P. \& Orcesi, A.D. A proposal for classification of key performance indicators for road bridges. 2017; IABSE 2017, Vancouver, Canada.

[3] Collin B, Carreaud P, Lançon H. High Efficiency Techniques for the Assessment of Railways Infrastructures and Buildings. Transportation Research Procedia. 2016; 14(0):1865-74.

[4] Camp G, Carreaud P, Lançon H. Large Structures: Which Solutions for Health Monitoring ? International Archives of the Photogrammetry, Remote Sensing and Spatial Information Sciences. 2013;XL5/W2(September):137-41.

[5] Carreaud P, Collin B. Apport et évolution des procédés semi-automatiques de relevé pour l'évaluation de l'état des structures de génie civil de l'espace souterrain. Journées GC'2017. Cachan: AFGC; 2017.

[6] Abraham O., Côte, P. Méthode impact-écho basse fréquence pour la détection de vide dans les gaines de précontrainte. - Bulletin des LPC, $n^{\circ} 239,2002$, LCPC : 41-50.

[7] Dérobert $X$, Abraham O., Aubagnac $C$. Review of NDT methods on a weak posttensioned beam before autopsy. In Proceedings of SPIE - The International Society for Optical Engineering 4758:365370. April 2002.

[8] Abraham O., Leonard C., Côte P. and Piwakowski B. Time frequency analysis of impact-echo signals: Numerical modeling 
and experimental validation. $\mathrm{ACl}$ Materials Journal. 2000; 612-624.

[9] Abraham O., Cottineau L.-M., Valade M. Bedaoui S. and Argoul P. Laser interferometer robot for the detection of voids in tendon ducts with the impact echo method. NDTCE'09, Non-Destructive Testing in Civil Engineering. Nantes, France, June 30th - July 3rd, 2009.

[10] Bore T., Taillade F., Placko D. Capacity probe for non destructive inspection of external post-tensioned duct: modeling by DPSM technique. $36^{\text {th }}$ annual review of progress in quantitative nondestructive evaluation, Rhode Island, USA, July 26, 2009, 8p.

[11] Terzioglu T., Karthik M. M., Hurlebaus S., Hueste M.B.D., Maack S., Woestmann J., Wiggenhauser H., Krause M., Miller P., Olson L.. Nondestructive evaluation of grout defects in internal tendons of posttensioned girders. NDT \& $E$ International. 2018; 99,23:35

[12] Zahn F. A. and Bitterli B. Developments in non-destructive stay cable inspection methods," in Proceedings of IABSE Symposium, 1995. 861-866.

[13] Xu F., Wang $X$. and $\mathrm{Wu} \mathrm{H.} \mathrm{Inspection}$ method of cable-stayed bridge using magnetic flux leakage detection: principle, sensor design, and signal processing. Journal of Mechanical Science and Technology. 2012; 26 (3): 661-669.

[14] Kim J.W., Park S. and Moon D.-J. Hidden Damage Detection for Main Cables of Suspension Bridges Incorporating DC Magnetization with a Search Coil-Based B-H Loop Measurement. 7th European Workshop on Structural Health Monitoring, Jul 2014, Nantes, France. 2014.

[15] Kharrat M. and Gaillet L. Non-destructive evaluation of anchorage zones by ultrasonics techniques. Ultrasonics. 2015; $61: 52-61$.

[16] Sluszka P, Gagnon C, Rankin S. Inspection, evaluation and monitoring of suspension bridge cables. ASCE Conference
Proceedings, Structural Engineering and Public Safety, 2006.

[17] Kurz J.H., Laguerre L., Niese F., Gaillet L., Szielasko K. Tschuncky R. and Treyssede F. NDT for need based maintenance of bridge cables, ropes and pre-stressed elements. J Civil Struct Health Monit. 2013; 3(4):285295.

[18] Zejli H., Laksimi A., Tessier C., Gaillet L., Benmedakhene S. Detection of the Broken Wires in the Cables' Hidden Parts (Anchorings) by Acoustic Emission. Advanced Materials Research. 2006; 13-14 :345-350.

[19] Laguerre L., Bouhelier M., Grimault A. Application of ultrasonic guided waves to the evaluation of steel members integrity. 2nd European Conference on Structural Health Monitoring (SHM), Munich, Germany, July 7-9, 2004.

[20] Laguerre L. and Treyssède F. "Non destructive evaluation of seven-wire strands using ultrasonic guided waves.", European Journal of Environmental and Civil Engineering, 2011, 15(4): 487-500.

[21] Laguerre L. , Durand O., Colin R. "Method for detecting a defect in a metal wire in a set of metal wires; in particular for an anchoring area of a civil engineering structure.", U.S. Patent Application No 15/560,481, 1 mars 2018.

[22] Schmidt F. and Jacob B. WIM data to assess consequences of new traffic regulations, IABMAS2010, The Fifth International Conference on Bridge Maintenance, Safety and Management, July 11-15, 2010

[23] Tinawi R., Lavigne D., Crépeau L., Sobhani E. The Existing Champlain Bridge Instrumentation, Monitoring and Load Tests. 39th IABSE Symposium - Engineering the Future. September 21-23 2017, Vancouver, Canada. 